\title{
Physical, chemical and biological process techniques and tools for pollution prevention and sustainability: an introduction
}

\author{
Eldon R. Rene ${ }^{1} \cdot$ Li Shu $^{2} \cdot$ Veeriah Jegatheesan ${ }^{3}$ \\ Published online: 13 March 2021 \\ (C) The Author(s), under exclusive licence to Springer-Verlag GmbH Germany, part of Springer Nature 2021
}

This special issue contains 17 articles that are disseminating the physical, chemical and biological process techniques and tools for pollution prevention and sustainability. They are selected from the presentations made at the $12^{\text {th }}$ annual international conference on "Challenges in Environmental Science and Engineering", CESE-2019 that was held in Kaohsiung, Taiwan, from the $3^{\text {rd }}$ to $7^{\text {th }}$ of November 2019. There were 181 delegates from 18 countries and regions who participated in CESE-2019. The conference covered 8 themes, namely (i) the Application of Membrane Technology \& NanoTechnology; (ii) Water \& Wastewater: Pollution Prevention \& Treatment; (iii) Resources \& Wastes: Management and Recovery of Materials and Energy; (iv) Air Pollution: Prevention and Treatment; (v) Sustainable Catchments \& Renewable Energy; (vi) Cleaner Production and Emerging Sustainable Practices; (vii) Appropriate Technology for Sustainability \& Climate Change Adaptation/Mitigation; and (viii) Soil Sustainability and Contaminated Soils and Sediments. This special issue covers various aspects of science and technological innovations, resource recovery, resource for health, recycling and its effects, treatment using

Responsible Editor: Philippe Garrigues

Veeriah Jegatheesan

jega.jegatheesan@rmit.edu.au

Eldon R. Rene

e.raj@un-ihe.org

Li Shu

li.shu846@gmail.com

1 Department of Water Supply, Sanitation and Environmental Engineering, IHE Delft Institute for Water Education, Westvest 7, 2611, AX Delft, The Netherlands

2 LJS Environment, 2 Parkville Avenue, Parkville, VIC 3052, Australia

3 School of Engineering, RMIT University, Melbourne, VIC 3052, Australia adsorbents, dissolved air floatation and plasma, controlling biofilm formation and the effects of air pollution.

An article is dedicated to evaluating the total factor productivity index of science and technology innovations in the coastal regions of China using the data collected between 2006 and 2016. Three articles are dedicated to resource recovery. One of them evaluates the economic feasibility of phosphorus recovery through struvite from the liquid anaerobic digestate of animal waste and another discusses the conversion of rice husk into fermentable sugar and silica using acidcatalyzed ionic liquid pre-treatment. The third article characterizes fractionated pyroligneous acid from palm kernel shell and studies its anti-inflammatory properties. Two more articles are related to recycling where one provides information on producing electronic grade hydrofluoric acid by recycling synthetic calcium fluoride and waste sulphuric acid. The second article investigates the influence of reusable polypropylene packing on ammonia and greenhouse gas emissions during sewage sludge composting using a lab-scale study.

Four articles are dedicated to adsorption/biosorption. The first article discusses the adsorption properties of functionalization vetiver grass-based activated carbon for the simultaneous adsorption of phosphate and nitrate. The second article evaluates the safety aspects and removal of ibuprofen via an Alternanthera philoxeroidesbased biochar. The third article analyses the effects of physicochemical properties of biochar derived from spent coffee grounds and commercial activated carbon on the adsorption behaviour and mechanisms of strontium ions $\left(\mathrm{Sr}^{2+}\right)$. The last article utilises environmentally friendly okara-based biosorbent for cadmium $\left(\mathrm{Cd}^{2+}\right)$ removal.

Five articles are dedicated to treatment. Two of them discuss about floatation technologies. One investigates the use of enhanced flotation technology using low-density micro-hollow beads to remove algae from a drinking water source and the other assesses the efficacy of dissolved air and flashpressurized flotations using low energy for the removal of organic precursors and disinfection by-products through a 
pilot-scale study. The third article optimizes process parameters to remove Cartap from simulated water matrix using a fluidized-bed Fenton process. The fourth article uses a twostep approach for arsenic removal by exploiting an autochthonous Delftia sp. BAs29 and neutralized red mud. The last article studies gas-phase isopropanol degradation by nonthermal plasma combined with $\mathrm{Mn}-\mathrm{Cu} /-\mathrm{Al}_{2} \mathrm{O}_{3}$. One of the last two articles conducts a review on the engineered topographies and hydrodynamics in relation to biofouling control and the last article carries out a human health-risk assessment based on chronic exposure to the carbonyl compounds and metals emitted by burning incense at temples.

The guest editors of this special issue are thankful to the Editor-in-Chief of Environmental Science and Pollution Research (ESPR), Professor Philippe Garrigues, and the publishing editor Alexandrine Cheronet for providing an opportunity to publish selected peer-reviewed papers that were presented at CESE-2019. Our special thanks to Ms. Fanny Creusot and Ms. Florence Delavaud, Editorial Assistants of ESPR and the entire production team at Springer for their valuable support in bringing out this issue successfully. Last but not the least, our sincere appreciation to all the reviewers for their invaluable and critical comments on all the manuscripts that were submitted for this special issue. The guest editors firmly believe that the special issue papers will be a useful reading document to your research group and we wish you all the very best.

Publisher's note Springer Nature remains neutral with regard to jurisdictional claims in published maps and institutional affiliations.

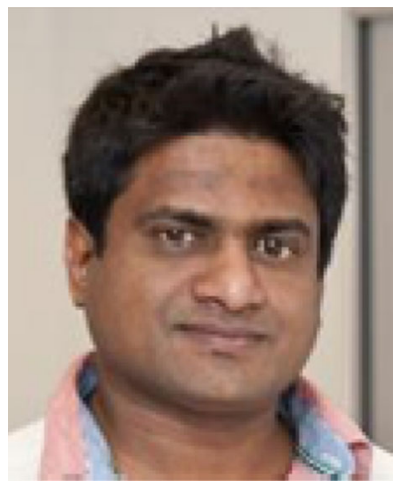

Eldon R. Rene $(\mathrm{PhD})$ is currently working as a Senior Lecturer at IHE Delft, Institute for Water Education, The Netherlands. He obtained his University Teaching Qualification (UTQ) diploma from IHE Delft and a PhD in Chemical Engineering from the Indian Institute of Technology Madras (India). Eldon's broad research interests are related to the development of biological treatment processes for wastewater and waste-gas treatment, resource recovery and the use of artificial intelligence tools for environmental monitoring and environmental process control. As a part of his capacity building initiative, Eldon regularly conducts scientific writing and skill development workshops at major international conferences/meetings, as well as for students from developing countries.

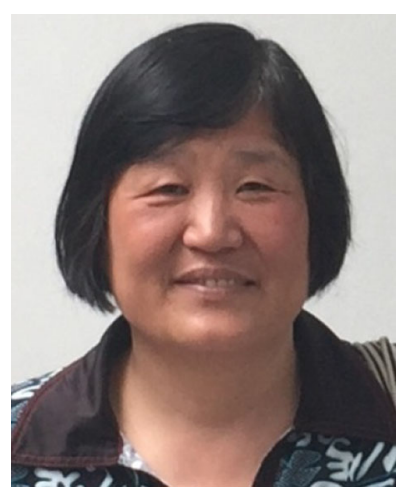

Dr. Li Shu is the Managing Director of LJS Environment, Australia, and a Guest Professor at Shandong Normal University. She was a Senior Researcher at RMIT University, Australia, until December 2016. Shu has more than 150 publications in the forms of Book, Book Chapters, Journal Papers and Refereed Conference Papers. She obtained her Bachelor degree from Qingdao University of Science and Technology, China; Master degree from Asian Institute of Technology, Bangkok; $\mathrm{PhD}$ from University of New South Wales, Sydney. She with her students and colleagues is the first to document images of water clusters taken by a microscope. They also proposed the structure of water. With the proposed structure of water, mysterious behaviours of water could be explained. The research group reported that $\mathrm{pH}$ of neutral salt was not 7.0 and the neutral salt was corrosive. Dr. Li Shu proposed that strong electrolyte such as $\mathrm{NaCl}$ existed in water as aggregates in 2005. The concept has been supported using a Nanosizer (Malvern) and results were published in 2013 and 2017. Li Shu's research interest is in water and wastewater treatment using membrane filters, resource recovery and zero liquid discharge. Various membranes and nanoparticles have been employed for water and wastewater reclamation. She taught Water and Wastewater Systems to undergraduate and post graduate students. She is one of the founders of an International Conference "Challenges in Environmental Science and Technology", CESE, and has been the Co-Chair of the Conference since 2008. She is an Editorial Board Member of Austin Environmental Sciences and SM Journal of Environmental Chemical Engineering. She is a guest editor of Journals: Bioresource Technology; Desalination and Water Treatment; International Biodeterioration and Biodegradation; Water, Air and Soil Pollution: Focus; Reviews in Environmental Science and Bio/Technology; Membrane Water Treatment.

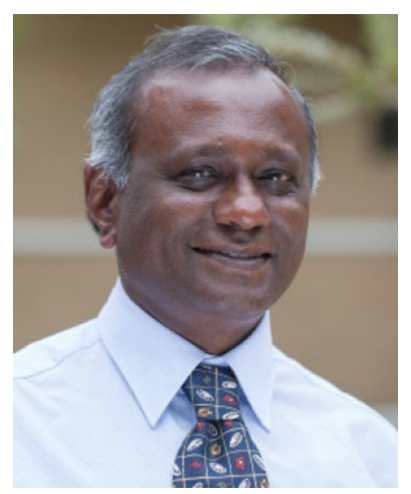

Veeriah Jegatheesan (Jega) is a Professor of Environmental Engineering and the Director of Water: Effective Technologies and Tools (WETT) Research Centre at RMIT University, Melbourne, Australia. Jega is the founder and Chairman of the international conference series on Challenges in Environmental Science \& Engineering (CESE) held annually since 2008 . Jega has conducted extensive research on the application of membrane bioreactors, sugar cane juice clarification, sea water desalination and the treatment of mine tailing ponds. He has over 400 publications including more than 160 peer-reviewed journal articles and five edited books. Jega is also the managing guest editor of 40 special issues in peer-reviewed journals. Recently, Stormwater Industry Association (Australia) has appointed him as one of the Governance Panel members for the Australian Stormwater Quality Improvement Device Evaluation Protocol (SQIDEP). Jega is the editorin-chief of a book series entitled Applied Environmental Science and Engineering (AESE) for a Sustainable Future published by Springer and has been instrumental for publishing 12 books since 2015. Jega has been appointed as the Editor-in-Chief of Environmental Quality Management journal (Wiley Publisher) from January 2020. 